\title{
The clinical cost of delays in switching therapy
}

\author{
Sharon Walmsley MD FRCPC
}

\begin{abstract}
S Walmsley. The clinical cost of delays in switching therapy. Can J Infect Dis Med Microbiol 2007;18(Suppl A):5A-7A.
\end{abstract}

\begin{abstract}
Management of the HIV patient with treatment experience continues to improve and evolve. New guidelines suggest that the goal of therapy should be maximal virological suppression. This is best achieved by using combinations of agents to which the virus is most likely to have some susceptibility and, where possible, by using agents within a new therapeutic class. The cases discussed demonstrate how the use of a potent regimen as salvage therapy can have good clinical, immunological and virological outcomes. However, if the salvage regimen selected is not potent enough to achieve these goals, the durability of the response is limited. The key lesson is that these strategies should be built on potency and agents should not be held back in case the strategy fails.
\end{abstract}

Key Words: Antiretroviral therapy; Enfuvirtide; HIV; Treatment experience

W hen patients experience virological failure, it is appropriate to switch to a new antiretroviral (ARV) combination. Successfully re-establishing control of viral replication is best achieved when new agents, especially those in new classes, are used in combination. The art of HIV medicine is knowing when and how to switch. The balance between early and late switching requires the availability of a regimen with sufficient potency, addressing patients' concerns about toxicities of new agents and ensuring that their immune system does not deteriorate. Leaving the patient on a failing regimen or selecting a regimen with inadequate potency results in further accumulation of resistant mutations, decreasing the chances of responding to other combinations later in the course of the disease. Thus, knowledge of what agents are or soon will be available and the clinical course of the patient can help to make those decisions.

The following cases outline the outcomes in two patients. Both patients were multidrug experienced and had virological failure. The patient who agreed to try a new combination including a new drug class - entry inhibitors - benefited, with improvements in his quality of life and CD4 count, and suppression of viral replication. The patient who hesitated to use the entry inhibitor in his salvage combination did not respond as well and later developed a new AIDS-defining illness.

Case 1

\section{CASE PRESENTATIONS}

Patient 1 is a 37 -year-old man who had been diagnosed with HIV infection in 1989. The year before his diagnosis, he experienced a number of illnesses suggestive of his underlying infection, including shingles, gastrointestinal Giardia species and Entamoeba coli infections, and recurrent genital herpes simplex virus infection. In 1989, treatment with zidovudine (ZDV; Retrovir, GlaxoSmithKline Inc) was initiated.

\section{Coût clinique des retards dans le changement de traitement}

La prise en charge des patients séropositifs pour le VIH ayant déjà reçu un traitement continue de s'améliorer et d'évoluer. Les nouvelles lignes directrices semblent indiquer que l'objectif du traitement devrait être une suppression virologique maximale. La meilleure façon d'y parvenir consiste à utiliser une combinaison d'agents auxquels le virus sera le plus vraisemblablement sensible et, si possible, des agents appartenant à une nouvelle classe thérapeutique. Les cas discutés démontrent comment l'utilisation d'un schéma thérapeutique puissant à titre de traitement de sauvetage peut avoir de bons résultats virologiques, immunologiques et cliniques. Toutefois, si le traitement de sauvetage retenu n'est pas assez puissant pour atteindre ces objectifs, la durabilité de la réponse est limitée. Ce qu'il faut retenir ici, c'est que ces stratégies devraient reposer sur la puissance du schéma thérapeutique et qu'il ne faut pas retarder l'instauration des agents en cas d'échec d'une stratégie.

In 1991, he had an acute hepatitis A infection, from which he recovered spontaneously. Basal cell carcinoma of the skin was diagnosed in 1993 and was treated with local resection.

His CD4 counts dropped from 380 cells $/ \mathrm{mm}^{3}$ in November 1993 to 250 cells $/ \mathrm{mm}^{3}$ in June 1995. In August 1995, he was enrolled in the Canada, Australia, Europe and South Africa (CAESAR) trial, in which he continued his ZDV, added didanosine (ddI; Videx, Bristol-Myers Squibb Canada), and was randomly assigned to receive lamivudine (3TC; Epivir, GlaxoSmithKline), loviride (an experimental non-nucleoside reverse transcriptase inhibitor [non-NRTI]), neither or both. The trial was closed in August 1996 by the study's safety monitoring committee because patients who received 3TC fared better than those who did not. When the trial was unblinded, it was determined that the patient had received both 3TC and loviride. At that point, his CD4 count was 232 cells $/ \mathrm{mm}^{3}$.

His poststudy treatment (January 1997) was switched to ZDV, 3TC and indinavir (Crixivan, Merck Frosst Canada Ltd). His viral load in October 1996 was 8196 copies/mL and it decreased to less than 400 copies/mL from January to May 1997. His CD4 count increased to 312 cells $/ \mathrm{mm}^{3}$ by May 1997.

Three months later, by August 1997, the patient's viral load had substantially increased to 25,970 copies/mL. Resistance testing was not available at the time, and his treatment was switched to stavudine (d4T; Zerit, Bristol-Myers Squibb Canada), 3TC, boosted saquinavir (Invirase, Hoffmann-La Roche Ltd, plus ritonavir [Norvir, Abbott Laboratories]) and nevirapine (Viramune, Boehringer Ingelheim Canada Ltd). His viral load subsequently dropped to below 400 copies/mL and his CD4 count was 396 cells $/ \mathrm{mm}^{3}$. He experienced nausea and diarrhea, which were controlled symptomatically.

In November 1998, the patient had a viral rebound to 6563 copies $/ \mathrm{mL}$. His CD4 count was 415 cells $/ \mathrm{mm}^{3}$. His

Division of Infectious Diseases, Department of Medicine, University of Toronto, and Toronto General Hospital, Toronto, Ontario

Correspondence: Dr Sharon Walmsley, Toronto General Hospital, 200 Elizabeth Street, 13EN Room 218, Toronto, Ontario M5G 2C4.

Telephone 416-340-3871, fax 416-595-5826, e-mail sharon.walmsley@uhn.on.ca 
saquinavir plus ritonavir doses were adjusted from $400 \mathrm{mg} / 400 \mathrm{mg}$ twice daily to $1000 \mathrm{mg} / 100 \mathrm{mg}$ twice daily, and he was switched to saquinavir (Fortovase, Hoffmann-La Roche Ltd).

During the subsequent period from 1998 to 2004, he was clinically well, with the exception of two episodes of bacterial pneumonia. During that time, his viral load ranged from 2000 copies/mL to 8000 copies/mL and his CD4 count ranged from 350 cells $/ \mathrm{mm}^{3}$ to 535 cells $/ \mathrm{mm}^{3}$ (20\% CD4). Liquid ritonavir was used for a short period because of issues with availability of the capsules. He had ongoing diarrhea that required treatment with loperamide (Imodium, McNeil Consumer Healthcare). He developed mildly elevated triglyceride and blood glucose levels. Both were initially managed with diet, but by April 2002, he developed frank diabetes, and treatment with oral hypoglycemics was initiated. His triglyceride levels continued to increase, as did his total cholesterol to high-density lipoprotein cholesterol ratio, and thus, statin therapy was initiated in 2003. He gradually developed a mixed fat redistribution pattern characteristic of lipodystrophy. He was also diagnosed with cutaneous Kaposi sarcoma, which was adequately treated with local irradiation.

In February 2005, the patient received antibiotics for a chest infection and subsequently developed Clostridium difficile diarrhea. It proved to be difficult to manage: although he responded to courses of metronidazole (Flagyl, Sanofi-Aventis Canada Inc) and/or vancomycin therapy, he continually relapsed when the drug was discontinued, and even when doses of vancomycin were slowly tapered.

His viral load increased from 2419 copies/mL in February 2005 to 12,530 copies $/ \mathrm{mL}$ in April 2005. His CD4 count decreased to 258 cells $/ \mathrm{mm}^{3}$. His C difficile infection was still uncontrolled. Genotyping and phenotyping, then available, were performed to identify treatment options. The patient was found to have multiple NRTI mutations (M41L, K43E, E44A, D67N, L74V, V118I, M184V, H208Y, L210W, R211K, T215Y, D218E and K219N) and protease inhibitor (PI) mutations (L10I, L24F, M46I, F53Y, L63P, A71V, V77I, I84V, L90M and L90M). He also had non-NRTI mutations at K103N and M230L.

Based on the genotype interpretation and limited susceptibility to NRTIs and PIs, the patient was entered into a clinical trial in May 2005 to allow him access to darunavir (TMC114; Prezista, Janssen-Ortho Inc), a new PI to be boosted with ritonavir, and a new class of drugs - an entry inhibitor, enfuvirtide was introduced. The regimen he received also contained multiple NRTIs, and included d4T, abacavir (Ziagen, GlaxoSmithKline, USA), tenofovir (Viread, Gilead Sciences Canada Inc), darunavir, ritonavir and enfuvirtide.

Since this switch in therapy, the patient's condition has markedly improved. His viral load dropped to less than 50 copies/mL in June 2005 and remained so in November 2006. His CD4 count increased from 334 cells $/ \mathrm{mm}^{3}$ in June 2005 to 373 cells $/ \mathrm{mm}^{3}$ in May 2006. During that time, vancomycin treatment was successfully tapered and the $\mathrm{C}$ difficile infection resolved. Glucose and lipid levels were controlled. His only complaint was a mild injection site reaction with enfuvirtide. He switched to the Biojector (a needle-free injection system; Biojector Medical Technologies, USA) and although he has continued to have a mild injection site reaction with erythema and nodules, he has found that he is able to cope. Other than the time taken to prepare and inject his therapy, he found that it has had little impact on his quality of life, which improved overall with the resolution of his diarrhea.

\section{Case 2}

Patient 2 is a 41-year-old man who was diagnosed as HIV positive in January 1992. At that time, he presented with thrush, which was treated with fluconazole, and ZDV therapy was initiated. Trimethoprim-sulfamethoxazole (Septra, GlaxoSmithKline Inc) was prescribed for Pneumocystis jiroveci pneumonia prophylaxis. In 1995, zalcitabine (ddC; Hivid, Hoffmann-La Roche Ltd) was added to ZDV, and in 1996, his treatment was switched to ZDV plus 3TC (Combivir, GlaxoSmithKline Shire Biochem). Full-dose ritonavir was added to this regimen in 1997. He subsequently developed elevated triglyceride and cholesterol levels, and thus, it was decided to replace ritonavir with indinavir, and ZDV with $\mathrm{d} 4 \mathrm{~T}$.

When referred in 1998, he had been receiving the combination of d4T, 3TC and indinavir for eight months. His CD4 count was at its highest ever at 300 cells $/ \mathrm{mm}^{3}$. His viral load, however, was never undetectable: it was lowest in 1996 at 537 copies/mL, peaked in 1997 at 16,890 copies/mL and was 600 copies $/ \mathrm{mL}$ at the time of referral. The treatment regimen was continued because few options were available, viral replication was at a low level and his immune system was well preserved.

In July 1999, his CD4 count had risen to 320 cells $/ \mathrm{mm}^{3}$, but his viral load had increased dramatically to 48,296 copies/mL. Therapy was switched to a combination of ddI, efavirenz (Sustiva, Bristol-Myers Squibb Canada), abacavir and nelfinavir (Viracept, Pfizer Canada Inc). Viral load initially decreased to 418 copies $/ \mathrm{mL}$, then rebounded to 11,000 copies $/ \mathrm{mL}$. CD4 levels decreased to 240 cells $/ \mathrm{mm}^{3}$ and remained stable at that level. The dyslipidemia, primarily recurrent increases in triglyceride levels, was managed with fenofibrate (Lipidil, Fournier Pharma Inc).

The patient was then enrolled in a structured treatment interruption (STI) trial in 2002, and was randomly assigned to a three-month STI. By the end of the STI, his CD4 count had decreased to 174 cells $/ \mathrm{mm}^{3}$, and his viral load had increased to 320,838 copies $/ \mathrm{mL}$. Before the STI, the patient's genotype included NRTI mutations at M41L, D67N, K103N, L210W and T215Y, and a PI mutation at V82F. During the STI, his plasma virus lost all mutations and he reverted completely to the wild type. He also felt more fatigued and developed a cold sore. His lipid levels normalized.

At the end of the STI, salvage ARV therapy was initiated with lopinavir plus ritonavir (Kaletra, Abbott Laboratories, USA), amprenavir (Agenerase, GlaxoSmithKline Inc), abacavir and ddI. His CD4 levels after this change in treatment peaked at 298 cells $/ \mathrm{mm}^{3}$, and his viral load initially decreased to 633 copies/mL, and then rebounded to 7713 copies $/ \mathrm{mL}$. His dyslipidemia recurred.

The patient entered a study in December 2002 and was randomly assigned to receive tipranavir (Aptivus, Boehringer Ingelheim Canada Ltd) plus ritonavir (Norvir, Abbott Laboratories). His baseline genotype included NRTI mutations at M41L, D67N, L74V, K103N, L210W and T215Y, and PI mutations at L10I, M46L, L63P, V82F and I84V. His treatment options were discussed with him, and enfuvirtide therapy was offered as part of the optimized background therapy. He refused enfuvirtide therapy because he could not accept the idea of injecting himself with needles. Also, he lived several hundred miles from the study centre and was concerned about receiving adequate support.

At study entry, his CD4 count was 216 cells $/ \mathrm{mm}^{3}$ and his viral load was 29,500 copies/mL. In addition to the tipranavir 
plus ritonavir, he received ZDV plus 3TC and tenofovir. His viral load initially decreased from 23,436 copies/mL to 20,313 copies/mL and then increased to 32,200 copies $/ \mathrm{mL}$. His CD4 count remained relatively stable at approximately 200 cells $/ \mathrm{mm}^{3}$ over the next year.

One year after entry into the study, the patient developed nausea, fatigue, headaches, aching, diarrhea and cough. His CD4 count was 206 cells $/ \mathrm{mm}^{3}$ and his viral load was 26,063 copies/mL. Investigations failed to reveal a cause for his symptoms. Changes in ARV therapy were discussed, but given his treatment experience and prior resistance patterns, little was available to build a new regimen. He lost $10 \mathrm{~kg}$ of body weight over the next six months, his CD4 count declined to 126 cells $/ \mathrm{mm}^{3}$ and his viral load increased to 39,417 copies/mL.

At this point, his treatment options were discussed with him again, and he continued to refuse enfuvirtide treatment, fearing the injections. He was seen three months later, when he had progression of his malaise, anorexia, further weight loss, cough, shortness of breath, lightheadedness, vomiting, abdominal cramping, fever and anemia. He underwent multiple investigations and was eventually found to have gastric non-Hodgkin lymphoma. He was treated with cyclophosphamide, doxorubicin, vincristine and prednisone chemotherapy, as well as granculocyte-macrophage colony-stimulating factor for neutropenia. He improved clinically, and the lymphoma entered into remission. His CD4 count remained low at 88 cells $/ \mathrm{mm}^{3}$.

New ARV therapy has been discussed with the patient. He has agreed to try a combination that includes enfuvirtide. However, there are no other active agents to combine with the new agent, and other drugs need to be recycled as part of a mega-highly active ARV therapy strategy.

\section{COMMENTS}

The cost of delays in switching treatment is illustrated by these two patients, both with long and complex treatment histories. Both patients had good adherence histories and had developed multidrug-resistant virus as a result of use of sequential monotherapies. For patient 2, the inability to introduce a new drug class, specifically the entry inhibitor enfuvirtide, together with a new boosted PI, has limited the potency of his salvage regimen. Although he had some response to therapy with a new boosted PI, because of inadequate control of viral replication he continued to accumulate resistance mutations over time, leading to the loss of treatment options and ultimately clinical failure. Patient 1 incorporated enfuvirtide together with a new boosted PI in his salvage regimen and had improvement in his clinical symptoms, marked increases in his CD4 cell count and viral HIV RNA suppression to less than 50 copies/mL for the first time since ARV therapy was initiated.

CONFLICT OF INTEREST: Dr Walmsley has served on consultation boards and speaker panels for Hoffmann-La Roche, Gilead Sciences Canada Inc, Tibotec, Abbott Laboratories, Bristol-Myers Squibb Canada, GlaxoSmithKline Inc, Pfizer Canada Inc, Merck Frosst Canada Ltd and Boehringer Ingelheim Canada Ltd. 


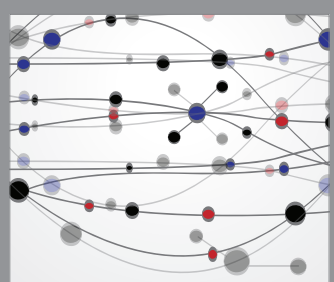

The Scientific World Journal
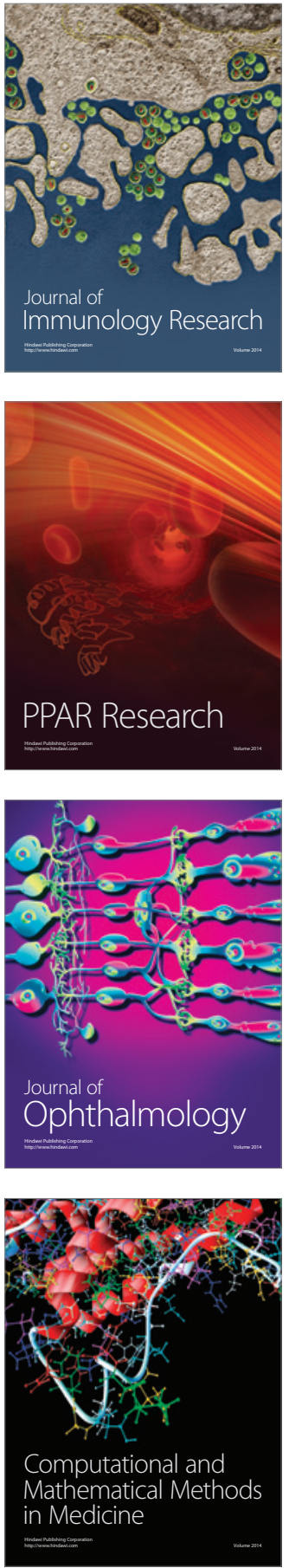

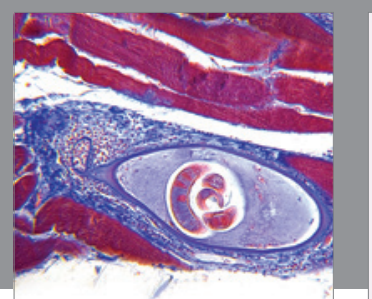

Gastroenterology Research and Practice

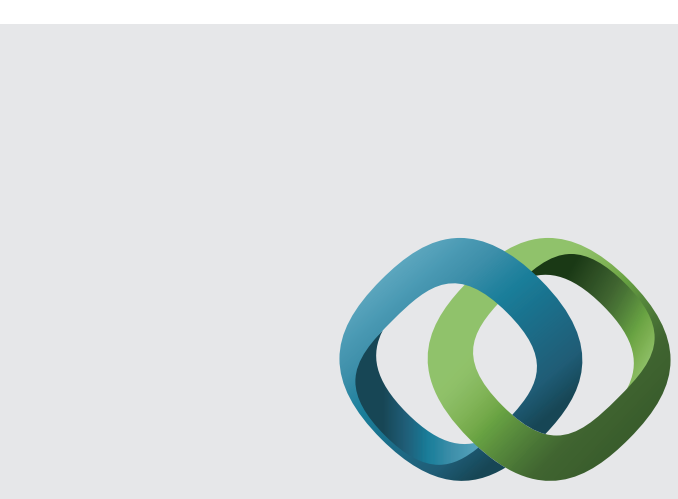

\section{Hindawi}

Submit your manuscripts at

http://www.hindawi.com
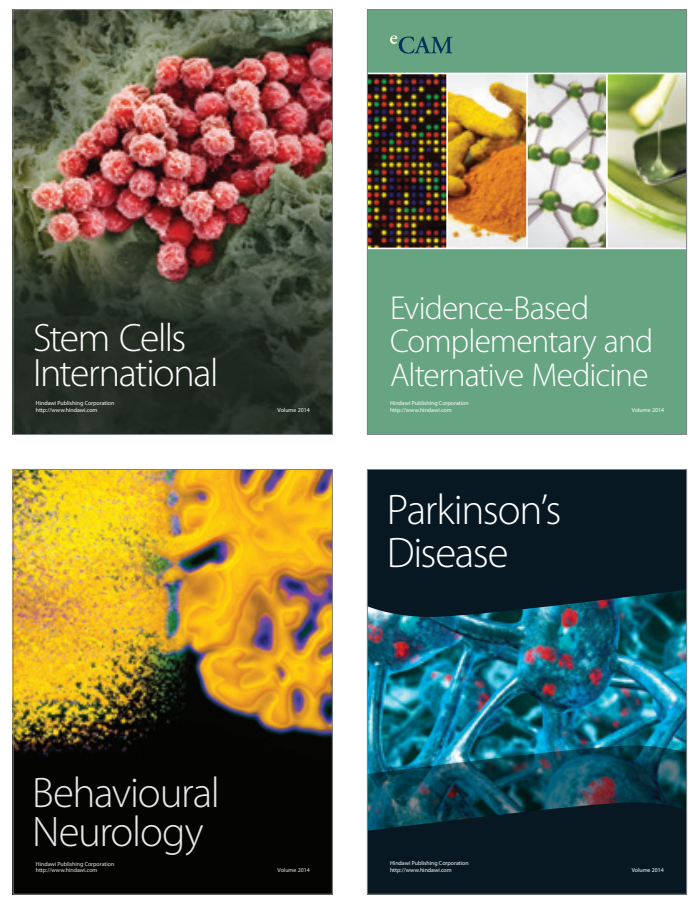
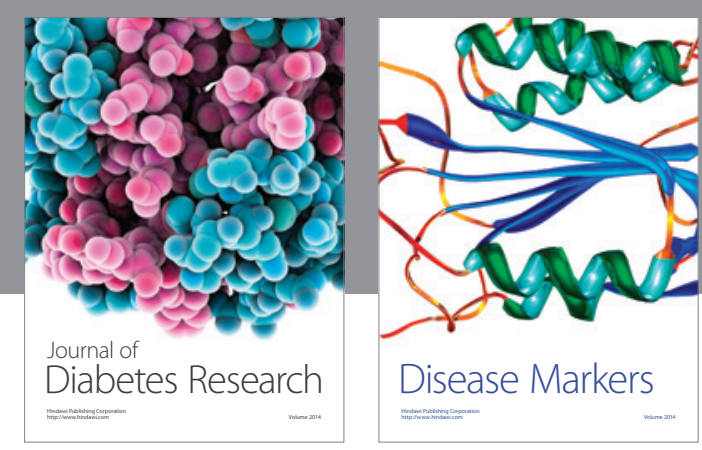

Disease Markers
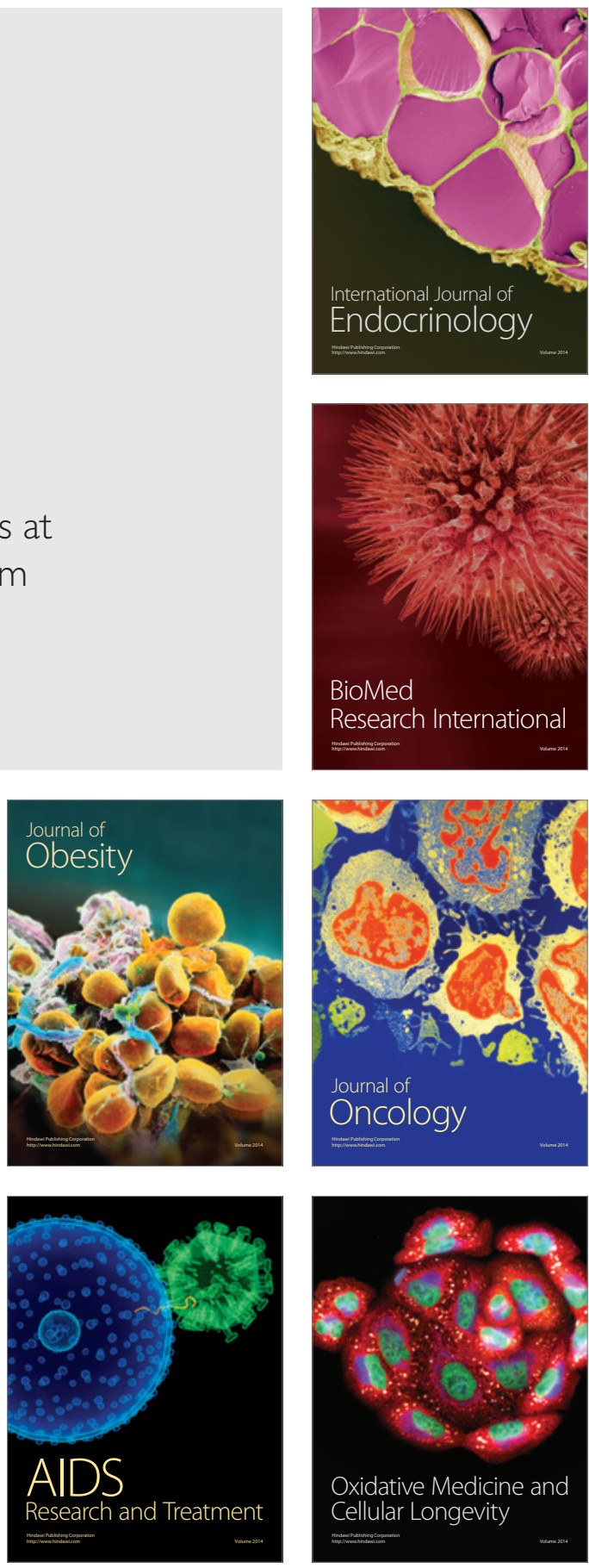